FURTHER OBSERVATIONS ABOUT' THE SURVEY OF FOREIGN AND INTERNATIONAL LAW COLIECTIONS IN SELECTED UNITED STATES LAW LIBRARIES: 1972-1973

By Igor I. Kavass*

GENERAL COMMENTS ABOUT LIBRARY SURVEYS AND THEIR IIMITATIONS

Library surveys, irrespective of their range of inquiry and specificity of information sought, can turn into incredibly taxing and even hazardous undertakings as those who have had the temerity to participate in them can vouch from personal experience. The primary objectives of such surveys consist of collecting relevant information from several similar library sources and the subsequent presentation of such information in a comprehensive and accurate manner. Unfortunately, a considerable degree of diver-

- Igor I. Kavass, Professor of Law and Law Librarian, Duke University, Durham, North Carolina 22706. 
gence exists between ideal surveys and the real world in which they are expected to be conducted.

In the first place, not all of the selected participants of a survey are able or willing to supply the requested information. Secondly, no matter how well or accurately the survey questionnaire is prepared, the information supplied inevitably differs from one set of replies to another. A possible explanation for this diversity in the nature and quality of responses is that libraries either do not apply the same criteria of evaluation with respect to their collections and services or, as happens in many cases, they simply do not have precise information about them. Such ladk of information is not really as unusual as one might think it to be. After all, how many libraries carry out regular inventories of their collections or keep accurate and continuous records of their reference and circulation activities? Furthermore, as surveys are usually conducted on a voluntary participation basis, opportunities to check the information and, more particularly, the numerical data supplied by the participating libraries are practically nonexistent, and tabulation of the reported data must frequently proceed on the basis of predominantly random samples. These inevitable imperfections of library surveys are bound to reflect all of the differences and inconsistencies furnished by the participating libraries without the means of correcting or adjusting them. Even where the discrepancies are apparent, they cannot be freely adjusted or corrected without the risk of giving offense to the participants who have taken the trouble to supply them.

Accepting the basic premise that library surveys, just like any other surveys, have these built-in limitations the question arises whether they have any intrinsic value at all and whether there is any merit in conducting them.

\section{THE SURVEY OF 1972}

The 1972 Survey of Foreign and International Law Collections in Selected Law Libraries of the United States [1 International Journal of Law Libraries 117 (1973)] is a case in point. Within the terms of its original inquiry it was optimistically conceptualized as a capacious project to collect and report in some detail the widest possible range of information about the content, development and maintenance of foreign and international law collections in a deliberately selected group of American law libraries which were known to have a special interest in the respective areas of law. A questionnaire, consisting of twenty-four questions and dealing with such matters as the dimensions and characteristics of foreign and international law collections (including holdings of periodicals, official gazettes, documents and doctoral dissertations), the frequency and rate of their use, the financial resources available for their development, and, last but not least, library personnel specializing in the relevant areas of law and legal bibliography, were distributed to the participating libraries. Soon, however, it became abvious, due to the paucity and unevenness of responses, that the 
initial expectations of the project were overly ambitious. In retrospect of subsequent experience the gap between information sought and received should not have come as a surprise when cognizance is taken of the inevitable fact that all library survey projects suffer from the same information deficiency to a greater or lesser extent and that most libraries lack complete and accurate statistical knowledge about their collections and operations even for their own internal purposes. It is not necessary to seek far to find an explanation for what may appear as a peculiar inability on the part of libraries to record and maintain complete and accurate statistics. The inevitable truth is that they are hopelessly caught in a vicious circle of trying to accommodate the constantly increasing demands of their growing numbers of users in a rapidly expanding world of available information resources. Chronically understaffed in view of their overextended services, libraries (and especially law libraries where the pressure of the information explosion is felt most) are encumbered with the maintenance of their daily routines to such an extent that they simply do not have the physical means to keep continuously accurate records about their holdings or operations. Even the exaggerated benefits of computers do not really help to solve their statistical problems because an efficient use of computers requires the use of expensive manpower which most libraries do not have the means to employ.

Absence of full and completely accurate information does not however mean that a survey should be abandoned or that its original scope of inquiry should be confined to a small number of innocuous questions. The first postulate of effective survey strategy is that the range of inquiry should extend far and wide, and imperfect answers or even a complete absence of response may still represent a valuable source of information, i. e., it may indicate an area of the survey in need of further and more intensive inquiry. Few surveys can pretend to report findings which are faultlessly perfect in accuracy. In spite of this obvious limitation, they may produce interesting and valuable items of information.

When the responses to the questionnaire for the 1972 Survey began to return, it became immediately apparent that the scope of inquiry had to be drastically reduced. In the first place, only thirty-two libraries of an already small group of forty-six libraries invited to participate in the survey responded to the questionnaire. The smaller number of participants had the effect of reducing the selected random sample to a dangerously low number for meaningful statistical inferences.

Secondly, very few of the participating libraries answered the questionnaire in full or with an acceptable degree of precision. Some libraries, e. g., Association of the Bar of the City of New York Library, returned perfect replies, but at the other end of the scale there were libraries which answered less than ten of the twenty-four questions. The worst example in this group of participating libraries was Duke University Law Library which, as the writer was subsequently able to find out and remedy for the purpose of 
the survey, answered five questions only, and four of them incorrectly. Thus, due to an inadequate number of responses, a meaningful random sample could not be obtained for the following important areas:

(i) the operative language perimeters of the respective library staffs,

(ii) holdings of official gazettes, foreign and international documents, and foreign doctoral dissertations, and

(iii) circulation and reference statistics for foreign and international law collections.

In other areas of the survey the submitted numerical data had to be extensively interpreted and extrapolated to achieve the most acceptable arithmetical mean for the sample of variables, and in some instances the data simply had to be reported without testing its veracity. The former approach was used in Table 2 of the Survey [1 International Journal of Law Libraries 117, at 129 (1973)] which listed the predominant country jurisdictions represented in the foreign law collections of participating libraries. The questionnaire directed the libraries to indicate approximate percentage breakdowns of their foreign law collections according to individual country jurisdictions. Nineteen libraries submitted this information in the required form, but the other thirteen libraries either presented general outlines of their collections without percentage breakdowns or gave no information whatsoever, except that some of them indicated in general terms the major country jurisdictions represented in their collections. Such serious divergences in the form of responses required that this particularly interesting and valuable item of information be presented descriptively and without supporting documentation. Admittedly, the legitimacy of information presented in such a general manner can be rightfully questioned in the appropriate circumstances, but it is doubtful that this is likely to be the case where the data is of a non-partisan nature, as in Table 2 . In any event, the alternative course of action would have been the complete omission of Table 2. This approach would have deprived readers of any information whatsoever about the major jurisdictional characteristics of some of the leading foreign law collections in the United States. Irrespective of its other intrinsic values, the omission of Table 2 would have constituted an unforgiveable and irresponsible exclusion of potentially valuable information. It is of course arguable that the table could have included more precise data about the foreign law collections of libraries which had supplied detailed information. In an effort to remedy this oversight, a supplementary table containing such data appears at the end of this paper.

The latter approach of reporting the data as it arrived and without attempting to perform any meaningful extrapolations therewith had to be used in Table 4 of the Survey [1 International Journal of Law Libraries 117 , at 139 (1973)] where the indicated number of periodicals series and subscriptions for many of the participating libraries happened to be smaller (!) than supplied to Professor Kurt Schwerin and the writer at about 
the same time for their 1973 Union List of Foreign Legal Periodicals in American Law Libraries [67 Law Library Journal 120 (1974)] which required more detailed and precise information about holdings of periodicals listed in the Index to Foreign Legal Periodicals. A note about this remarkable inconsistency in the two concurrent surveys on the same broad topic was included at the end of Table 4. An interesting sideline of the inconsistency is that it refutes the commonly held belief about institutional propencity towards progressive dilation of statistics. Instead of reporting, as was to be expected, a larger number of periodicals, the participants chose to err in favor of a smaller number.

With all of these qualifications in mind about its ambitious original objectives and the eventual limitations of available information, the Survey had to be confined to seven major areas of inquiry where the reported data was sufficiently meaningful for marginal correlations. In order of their appearance in the Survey [1 International Joumal of Law Libraries 117, 126-133 (1973)], these areas were:

Table 1: size and growth of collections,

Table 2: jurisdictional areas of concentration,

Table 3: classification systems,

Table 4: holdings of periodicals,

Table 5: employment of foreign and international law librarians,

Table 6: special topical and geographical areas of interest, and

Table 7: financial information.

\section{POSSIBLE BENEFITS OF THE 1972 SURVEY}

The potential value of the Survey, in spite of its inevitable and deeply regrettable abandonment of some areas of inquiry due to paucity of information, becomes obvious even by briefly scanning through this abbreviated list of its data tables which range over a broad area of subjects; and in this respect it may be pointed out that Tables 3 (classification systems), 6 (special topical and geographical areas of interest) and 7 (financial information) have the unique quality of being especially useful to anyone interested in the development of foreign and international law collections.

\section{PROBLEM AREAS IN SURVEYS}

In view of the preceding observations about the chronic problems of survey projects it is normal to expect some minor (or even major) deficiencies in the detailed presentation of the available data. Such deficiencies fall into three clearly discernible classes. Some of them may be caused by questions in the original survey questionnaire being prone to conflicting interpretations which, in their turn, may lead to different answers being submitted by the individual participating libraries. Safeguards against these types of inconsistencies were taken in the 1972 Survey, but they were not always completely successful. Other discrepancies can arise through submis- 
sion of incorrect information by participants of a survey. Finally, some discrepancies are simply typographical or arithmetical errors.

\section{COMMENTS BY ADOLF SPRUDZS}

I am grateful to my colleague Adolf Sprudzs for drawing my attention in his recent Comments on Foreign Law Surveys [2 International Journal of Law Libraries 84 (1974)] to some of these deficiencies and discrepancies in the 1972 Survey of Foreign and International Law Collections in Selected Law Libraries of the United States. Specifically his comments are concerned with several tables appearing in this Survey which purport to contain numerical information about monographic and periodical holdings of foreign and international law collections. His exceptionally fair and analytically careful remarks are of such an overall importance to the reading of the Survey that responding to them in effort to remove at least some points of error or likely confusion is the least I can do. There is, however, a preliminary matter of significant importance which I must mention. Failure to do so may result in an unnecessary misunderstanding of Sprudzs' and my perceptions about the aims and functions of library surveys.

My agreement with Sprudzs' critical comments about specific errors or omissions in the 1972 Survey does not constitute an unqualified acceptance of his general thesis about the immeasurability of several foreign and international law collections because they ladk a common denominator in a given situation or because they do not have a uniform system of classification and nomenclature. If such rigidly common elements constitute indispensable prerequisites for survey projects, then all types of comparative library statistics are suspect, and comparative data about foreign and international law collections must remain forever inaccessible. It is a matter of common knowledge within the profession that law libraries do not use identical statistical methods or arrangements. The differences in their approaches are however so marginal that they do not preclude valid comparisons. In fact, such comparisons are effectively made by law libraries on an almost permanent basis.

\section{THE PLACE OF RELATTVE STATISTICS IN IIBRARY SURVEYS}

Acquisition of perfectly correlated statistical data, whilst it is a desirable ideal, is a prohibitively expensive undertaking so that in the actual world of financial restraints a sample gatherer is continuously relegated to a position of relative evaluations and approximate numbers. The real question in these circumstances is whether the available data, irrespective of its imperfections, can be effectively utilized to establish meaningful correlations between individual samples. It is submitted that it can. Taking foreign and international law collections in American law libraries as a case in point, it is well known that the total number of books in such collections does not 
constitute an infinite quantity. The probable highest number of books for the whole or any part of such collections can be fixed with a reliable degree of approximation which places statistically tolerable percentage limits on their individual numerical abberations irrespective of whether they are caused by differences in classification systems, imperfect inventory records or simple arithmetical errors. For example, subject to the adjustment of the actually submitted figures either by an addition or subtraction of a numerical abberation caused by an expressed deviation from the requested data, it is possible to infer that holdings of international law materials do not exceed thirty per cent of any foreign and international law collection represented in the sample. It is true that such information may not be accurate in absolute numbers for a particular library participating in the survey but, in the absence of more precise information, it represents a meaningful and tangible guideline.

Impèrfect statistics of finite quantities, such as collections of legal materials, also have other valuable applications. For example, comparative information about collection sizes, available financial resources, areas of interest and rates of growth may help to determine which of the many variables in the development and management of a foreign and international law collection are independent and what is their relationship to the respective dependent variables. Once again, such information can assist in the formulation of useful hypotheses relating to the future development of collections as well as improvement in their management.

It is unlikely that any statistical surveys attain the degree of unequivocal perfection in terms of their common denominators. Even such respectable surveys as the survey of law school libraries, conducted on behalf of the Association of American Law Schools, or the more elaborate survey of crime statistics, issued by the Federal Bureau of Investigation, are frequently accused of reporting distortions. Yet their general usefulness remains unimpaired. Thus, for instance, the law school library surveys by the Association of American Law Schools are continuously used with good results in the planning and development of law libraries. Though their statistical data may mean different things to different people, they establish nevertheless helpful guidelines of a general nature.

\section{STATISTICAL OBJECTIVES OF 1972 SURVEY}

The statistical data in the 1972 Survey of Foreign and International Law Collections in Selected Law Libraries of the United States was never intended to be of a completely precise comparable nature, and the survey report contained several caveats to this effect. For this reason the information received from the participating libraries was reported in accordance with their own classification concepts of foreign and international laws, and there was justifiable expectation that their individual concepts ranged within the same broad parameters. Furthermore, as most of the participating libraries preferred to supply the information in round numbers, this method 
was also used, wherever applicable, in the Survey. It was thought that this information, though not perfectly comparable, would have an intrinsic general utility to anyone interested in the overall growth of foreign and international law collections and the approximate correlation of such collections in spite of some relative differences in their respective classification systems. It was also thought that the different criteria, which the participating libraries adopted for purposes of reporting their information, were too marginal to create a serious obstacle to such comparisons.

In fact, the expectations were fully justified. The majority of participating libraries, which chose to submit detailed information, made their estimations along more or less the same conceptual lines so that the differences in their reporting methods did not distort their combined statistics to such an extent as to make them completely meaningless. It would seem, therefore, that the statistical data was adequate and sufficiently relevant to establish an acceptable basis for valid comparisons of a relative or general nature. For what it is worth, some of the information from the Schwerin Survey of 1960 was presented in Table 1 of the 1972 Survey for exactly the same reason. It was hoped that it would give a broad comparative overview of the approximate rate of growth in the sizes of the respective collections during the period of twelve years between the two survey dates even though the Schwerin Survey data was based on a slightly narrower class of materials.

Actually, divergences in classification systems and terminology were not the major problems of the 1972 Survey. The participating libraries fully understood the parameters of the information sought in the questionnaire. The conceptual differences in their responses were not significant, and they clearly stated their more substantial departures from such concepts where they were forced to make them for one reason or another. The more serious problem was that many of the libraries simply did not possess the required information, and their responses were expressed in very general terms.

\section{REPLIES TO SPECIFIC COMMENTS BY ADOLF SPRUDZS}

My responses to Sprudzs' specific remarks about the 1972 Survey should be read in the context of these preliminary observations.

\section{Table 1}

The major thrust of Sprudzs' criticisms about the weaknesses of foreign law surveys is directed at Table 1. Quite appropriately he points out that this table is not suitable for a precise comparison of the respective library holdings of foreign and international law collections because some of the participating libraries included British and "Commonwealth" materials in their total figures, as they were expected to do, whilst other libraries did not do so. In fact, three libraries only-University of Chicago, University 
of Illinois, and University of Wisconsin - did not report their holdings of British and "Commonwealth" materials. Yale University included some of the "Commonwealth" materials in its total count of foreign law holdings, but excluded British materials. All other participating libraries followed the general tenor of the questionnaire by reporting their holdings of British and "Commonwealth" materials. Sprudzs is absolutely right, however, to point out that an appropriate note to this effect should have been included in Table 1.

A further criticism of Sprudzs is that the inclusion of information from the Schwerin Survey of 1960 did not serve a useful purpose because it was based on a narrower class of materials than the 1972 Survey. I have mentioned already that such information may still have its uses for general comparative purposes, especially as a note at the end of Table 1 briefly describes the classes of materials excluded from the Schwerin Survey.

As far as the discrepancies in the holdings of Northwestern University are concerned, it is the writer's sole responsibility. He happened to be in charge of answering the questionnaire at Northwestern University when the 1972 Survey was conducted, and he made certain that the collection figures included holdings of British and "Commonwealth" materials. By an unfortunate happenstance of circumstances he made an arithmetical error in computation of the total holdings.

Table 2

Reasons for the brevity of this table are described elsewhere in this paper. Sprudzs' criticism that the conclusions about the predominant jurisdictional holdings in the participating libraries should have been supported by at least some documentation is well made. An attempt to remedy this oversight is made by publishing a supplementary table at the end of this paper. Table 4

Sprudzs outlines the possibilities of many inconsistencies in the reporting base for the figures of periodical holdings as they appear in this table. No doubt, the argument about some of the participating libraries reporting all of their foreign periodical holdings whilst other libraries reporting only those periodical holdings which are indexed in the Index of Foreign Legal Periodicals may be valid provided that it can be established that the participating libraries were able to make such distinctions in their internal statistics. It may even have been desirable, if they had done so. The additional information, though divergent, would have established several additional variables for a further study of foreign periodical holdings in these libraries. In actual fact, the information submitted for the Survey did not reach such level of sophistication. Many of the responses contained figures which were quite obviously too low even to reach the probable number of periodical series received by the participating libraries.

As far as the appearance of the word "serials" in this table is concerned, it should be explained that it is a typographical error. It should have been "series" in both instances where it appears in the table. 


\section{CONCLUSION}

There is no doubt that a more precise and detailed survey of foreign and international law collections is highly desirable. Whether a survey of this kind can effectively be carried out in such conditions as prevailed during the performance of the 1972 Survey is doubtful. It would have to be a project of considerable magnitude conducted by an independent team of specialists, who would be temporarily detached from their regular working commitments so that they could devote their full time to the collection and analysis of relevant information. Furthermore, the team would require sufficient funds to have the means of surveying personally the collections of the participating libraries (of course, with the approval of these libraries and the assistance of their respective staffs). They could then make immediate adjustments and correlations in the data so that it would fall in within the common denominators of the survey objectives. Perhaps, if a project of this grand design were possible, the survey would achieve a greater degree of precision and comparable uniformity.

But where are the supporting funds to come from? In this context it may be relevant to mention that after the conclusion of the 1972 Survey this writer approached several foundations with a suggestion that a grant be made to the American Association of Law Libraries for the purpose of enabling it to carry out a more thorough survey of foreign and international law collections of its member libraries. Of the few foundations, which deemed it necessary to reply to the writer, all expressed regret that they were not interested in a project of this nature.

It must be remembered that the 1972 Survey of Foreign and International Law Collections in Selected Law Libraries of the United States was conducted without the aid of any supporting funds by one person only. On the whole, it was a prosaic "labor of love" motivated by a compelling desire to perpetuate the standards of professionalism in foreign and international law librarianship established some twelve years earlier by the Schwerin Survey.

In view of its many constraints it is not surprising that the findings of the Survey turned out to be proximate and relative. They did, however, provide a wealth of information which, but for the Survey, would not have seen the light of day. As it stands, the Survey presents a sufficiently valid profile of foreign and international law collections in American law libraries to give the profession a fairly good idea about the character of such collections as well as their strong and weak points. Even if the Survey is considered deficient in other respects, it has at least the merit of establishing beyond a shadow of doubt the need for further and more detailed investigations of the individual areas of foreign and international law collections so that a better knowledge may be gained about them. 